\title{
RESÍDUOS SÓLIDOS URBANOS E A GESTÃO AMBIENTAL NO PONTAL DO PARANAPANEMA
}

\author{
Agessander Manoel, Munir Jorge Felicio \\ Universidade do Oeste Paulista - UNOESTE, Mestrado em Meio Ambiente e Desenvolvimento Regional, \\ Presidente Prudente/S. E-mail: agessandermanoel@hotmail.com
}

\section{RESUMO}

Este estudo participa das discussões sobre os dilemas da gestão dos resíduos sólidos urbanos a partir das análises teóricas e das constatações de um trabalho de campo. Apresenta a realidade histórica e discute as propostas públicas referentes à gestão dos resíduos sólidos urbanos, descrevendo e comparando as práticas existentes em alguns municípios e seus possíveis impactos ambientais, econômicos e sociais provocados pela deposição inadequada dos rejeitos. Constata-se que a falta de informação sistematizada e periódica são fatores que interferem na implantação da gestão de resíduos sólidos e que as formas de utilização, organização e exploração do trabalho na catação dos resíduos sólidos recicláveis possuem potencialidade na obtenção de melhores resultados.

Palavras-chave: Resíduos Sólidos Urbanos, Gestão Ambiental, Reciclagem.

\section{SOLID WASTE AND ENVIRONMENTAL MANAGEMENT IN PONTAL}

\begin{abstract}
This study takes part in discussions on the management of the dilemmas of municipal solid waste from the theoretical analysis and the findings of fieldwork. It presents the historical reality and discusses public proposals for the management of municipal solid waste, describing and comparing the practices existing in some municipalities and their potential environmental, economic and social impacts caused by improper disposal of waste. It appears that the lack of systematic and periodic information are factors that interfere with the implementation of solid waste management and forms of use, organization and exploitation of labor in scavenging recyclable waste have potential in getting better results.
\end{abstract}

Keywords: Solid Waste, Environmental Management, Recycling 


\section{INTRODUÇÃO}

O tratamento dado aos resíduos sólidos teve nova perspectiva a partir da Lei 12.305/10, a qual instituiu a Política Nacional de Resíduos Sólidos onde dispõe seus princípios, objetivos e instrumentos. Este marco regulatório discute a regra legal com a qual orienta e direciona a devida adequação aos resíduos sólidos. Todavia, ela se absteve de fornecer o caminho pratico para a aplicabilidade ambiental, social e econômica. Na data da publicação da lei foi estipulado ao poder público municipal um prazo de quatro anos (2014) para adequar suas ações e estruturas à Política Nacional de Resíduos Sólidos.

A discussão será desdobrada sob o olhar de pesquisadores que se servem de um referencial empírico de outras áreas, impulsionando um trabalho interdisciplinar para uma possível compreensão do fato como um sistema aberto, vivo e complexo. Assim, a abordagem da gestão dos resíduos sólidos urbanos buscará um entendimento com a questão ambiental, social e humana, centrada na discussão conjunta da sustentabilidade econômica, social, política e ambiental, visando sempre respeitar suas áreas e necessidades, mas objetivando um consenso regido por princípios científicos.

O objetivo principal deste estudo é debater os resíduos sólidos urbanos e a gestão ambiental no Pontal do Paranapanema, tendo como base empírica os municípios de Presidente Prudente, Pirapozinho, Álvares Machado e Tarabai.

\section{METODOLOGIA}

A pesquisa segundo Rampazzo (2004, p.49) "é um procedimento reflexivo, sistemático, controlado e crítico que permite descobrir novos fatos ou dados, soluções ou leis, em qualquer área do conhecimento". Assim, este procedimento permitirá entender melhor a realidade desta temática, além de observar vários aspectos, uns coincidentes, outros nem tanto. Essa busca na pesquisa precisa obedecer a critérios e normas a partir da base empírica na qual se encontra a questão a ser estudada. Neste conjunto, portanto, se encaixa o objeto desta pesquisa, os resíduos sólidos urbanos e seu objetivo, a gestão ambiental no Pontal do Paranapanema que permeia as leis, ações e resultados ambientais esperados.

Dentre os procedimentos metodológicos a primeira etapa é o levantamento bibliográfico sobre a temática, buscando pesquisadores que discutam a gestão dos resíduos sólidos. Para Lakatos e Marconi (2005, p. 185) a "pesquisa bibliográfica, ou de fonte secundaria, abrange toda bibliografia já tornada publica em relação ao tema estudado" o que é ratificado por Koche (1997, p.122), ao expressar que "a pesquisa bibliográfica se desenvolve tentando explicar um problema, utilizando um caminho disponível a partir das teorias publicadas em livros ou obras congêneres".

Para abordar os resíduos sólidos e a gestão ambiental no Pontal do Paranapanema, as cidades de Presidente Prudente, Pirapozinho, Álvares Machado e Tarabai foram escolhidas por apresentarem base empírica com potencial de análises e comparações onde serão realizados trabalhos de campo com a intenção de conhecer a realidade existente buscando um levantamento e análise de legislações municipais e planos diretores nos respectivos municípios referentes ao gerenciamento de resíduos sólidos; análise do transporte e disposição dos resíduos sólidos domiciliares e visitas aos locais de disposição dos resíduos sólidos nos municípios.

\section{RESULTADOS}

Segundo Bezerra (2015) a promulgação da Lei Federal 12.305/2010 e seu Decreto regulamentador 7.404/2010, que juntos instituem e regulamentam a Política Nacional de Resíduos Sólidos traz as diretrizes, os princípios e objetivos que representam uma série de desafios para a gestão integrada de resíduos sólidos, pois o problema central está na forma de como se dará o processo de implantação e efetivação desta proposta legal. A implantação de aterros sanitários e de serviços de reciclagem, compostagem e tratamento de resíduos previstos pelo governo federal 
pela Lei 12.305/10 teve a necessidade de ser prorrogada para mais quatro anos (2018) devido a impossibilidade de sua plena execução que objetiva a extinção de todos os lixões em todos os municípios brasileiros.

A administração entende que o que difere as empresas não é matéria prima, processos de transformação, tecnologia, ou outros fatores que podem ser conseguidos no ambiente empresarial por qualquer instituição, mas o responsável pela orquestração destes componentes, o administrador. Embora seja uma ciência relativamente nova, produziu transformações que afetaram todo o sistema socioeconômico mundial, pois transforma conhecimento em produtividade. "Até bem recentemente, ninguém sabia como reunir pessoas com diferentes habilidades e conhecimentos para alcançar metas comuns" (DRUCKER, 2002, p.198). Para Drucker (2002) a administração não deve ser restringida ao conceito de administração de empresas.

Anteriormente o Estado ditou como deveria ser trabalhada a política ambiental no país, mas foi somente com a criação do Ministério do Desenvolvimento, Urbanização e Meio Ambiente em 1985, que se apercebeu da importância dos atores sociais, para conjuntamente discutirem e proporem formulação, implementação e gestão das políticas ambientais. Esta mudança de atitude governamental permitiu trazer a discussão princípios administrativos que se preocupassem com os impactos sociais, analisando e propondo medidas para transformar estes impactos em novos negócios.

Somam-se às análises de Drucker (2002) as de Cunha e Guerra (2008) pela importância delas ao apresentar uma retrospectiva da questão ambiental. Eles explicam que a partir de 1930 o processo de implementação de uma política ambiental começa a ser discutido pelo Estado, juntamente com o surgimento da revolução industrial. No início da década de 1970 a percepção dos efeitos da degradação do planeta chama a atenção em virtude de sua irreversibilidade catastrófica impondo a necessária elaboração e implementação de políticas públicas ambientais, embora muitos intelectuais já se manifestassem a esse respeito, como, por exemplo, Carson (1969).

A capacidade de suporte de recursos naturais do planeta encontra-se abaixo das projeções de proporcionalidade do crescimento populacional, ressaltam Cunha e Guerra (2008). O Estado tem provido a sociedade de uma legislação ambiental completa, contudo o maior desafio esta em transformar as leis aprovadas, em prática social. A aplicabilidade e gestão destas propostas ficam comprometidas, pois os instrumentos de sua aplicabilidade ora não ficam explícitos na lei, ora o Estado não prove condições de sua aplicação, ora não disponibiliza condições financeiras para sua fiscalização e cumprimento entre outras lacunas vistas no processo final.

O trabalho de Cunha e Guerra (2008) é fundamental para se entender o processo da questão ambiental no Brasil. Entretanto para atingir o objetivo de analisar a realidade histórica sobre a gestão dos resíduos sólidos urbanos na Região do Pontal do Paranapanema; discutir as propostas públicas e descrever e comparar as práticas adotadas faz-se necessário dialogar com outros pesquisadores. Leal (2004) está entre os pesquisadores que se interessaram pelo tema ao construir o diagnóstico da produção, tratamento e destinação final de resíduos sólidos e as formas de organização dos catadores.

As análises de Leal (2004) ressaltaram que o interesse do poder público municipal se restringe aos resíduos sólidos domiciliares e a dos serviços de saúde. Não há na maior parte dos municípios um controle ou informações relativas às quantidades geradas de resíduos de outras origens. Essas e outras constatações indicam a carência de controle da produção de resíduos sólidos e às estimativas feitas com base em médias diárias de produção per capita. Isto demonstra a necessidade de implantar sistemas de gestão que organizem e sistematizem dados e informações sobre resíduos sólidos nos municípios, cujo interesse está presente nessa proposta de pesquisa. 


\section{DISCUSSÃO}

As análises de Leal (2004) foram reforçadas pelas contribuições de Gonçalves (2006) ao ampliar a compreensão dos dilemas e impasses quanto à gestão dos resíduos sólidos urbanos quando demonstrou o desenvolvimento das formas de utilização, organização e exploração do trabalho na catação dos resíduos sólidos recicláveis nos lixões e a inserção desses trabalhadores no circuito econômico.

Para Gonçalves (2006) as diversas dimensões do circuito econômico e de estruturas de poder e do controle social são consideradas como elementos de atrelamento e subsunção às leis de mercado. Fica claro que o trabalho na catação de resíduos recicláveis é, na atualidade, o elemento fundamental deste circuito econômico, sendo à base de sustentação dos índices de reciclagem de resíduos e dos ganhos que a indústria brasileira envolvida neste setor vem alcançando nos últimos anos. Os trabalhadores, no entanto, estão sempre expostos aos riscos de lidar diretamente com os mais diferenciados tipos de resíduos, submetendo se a uma situação de contato com agentes contaminantes nocivos a saúde, sem que isso se reverta em melhores rendimentos.

Gonçalves (2006) aborda ainda o fechamento de alguns locais de aterro de lixo para evitar a entrada e o trabalho dos catadores, sendo esta a única maneira encontrada pelo poder publico, em alguns municípios, para adequar-se as normas ambientais estabelecidas, evitando as sanções por parte dos órgãos fiscalizadores. O planejamento e a gestão ambiental e territorial passam, portanto, pela necessidade de propor uma visão adaptativa do processo com ações seqüencialmente planejadas, encadeadas e não isoladas, que levem em conta as características e forças que as induziram para contrapor uma situação a este desequilíbrio e degradação ambientalsocial existente e não desejado, por propostas múltiplas, que tenham combinações múltiplas e variadas, permitindo caminhar para uma situação planejada favoravelmente, mas ao mesmo tempo, consciente de que o sistema fará os ajustes necessários para seu equilíbrio.

Reforçando o pensamento de Gonçalves (2006), Rodriguez e Silva (2013) discutem que o planejamento de gestão ambiental e territorial não deve ser visto como um fator isolado, mas sim como sistemas e estruturas complexas interligadas e entrópicas da parte da natureza e da sociedade, que se alteram a cada estímulo recebido, em maior ou menor intensidade e complexidade, independente da parte, apresentando uma retro-alimentação constante. É impossível se falar em um planejamento e gestão ambiental e territorial, sem uma visão sistêmica para compreensão das propriedades dos geossitemas naturais.

Para Rodriguez e Silva (2013), dentre as propriedades sistêmicas, devemos em primeiro plano entender a estrutura do geossistema, que tem seu comportamento definido por uma cadeia temporal linear e mecanismos de retro-alimentação e que podem alterar a seqüência de ações bem como por ações não programadas por estarem ligados por cadeias de causa e efeito. Este pensamento se integra ao de Araujo, Nascimento e Vianna (2014), que apresentam que vários autores propõem a concepção de que a humanidade está vivendo na Era do Antropocentro.

O paradigma da prosperidade e os desafios para a vida humana no planeta se deparam com o questionamento de qual modelo seria mais eficiente para atender ás necessidades humana sem distinção, de forma includente e ambientalmente correta, uma vez que "se ainda é possível a sobrevivência humana no planeta, isso se deve às imensas desigualdades sociais que privam de condições de vida decente uma grande parcela da população" (ARAUJO; NASCIMENTO; VIANNA, 2014, p.11).

Capra (1996) apresenta A Teoria dos Sistemas, que é baseada em critérios, onde o primeiro deles consiste na mudança de compreensão das partes para o todo, pois as propriedades pertencem ao todo e não existem na sua plenitude nas partes. Ao dissecar o todo em partes, as propriedades sistêmicas do todo desaparecem. Assim, apresenta que há sistemas dentro de 
outros sistemas e suas propriedades não podem ser compreendidas por meio de análise das partes, mas sim dentro do contexto maior.

Com a discussão das partes para o todo, Capra (1996) amplia sua compreensão a partir das análises Bertalanffy que considera os organismos vivos como sistemas abertos, não sujeitos a termodinâmica clássica, uma vez que esta atua bem com sistemas fechados, emergindo a interdisciplinaridade como processo dinâmico para compreender as alterações no meio ambiente interconectando as diversas áreas do saber científico.

Estas discussões da questão e gestão ambiental muito contribuem aos estudos da gestão dos resíduos sólidos no Pontal do Paranapanema, pois as ações quanto ao tratamento dado aos resíduos sólidos urbanos não se limita a Lei $12.305 / 10$, que instituiu a Política Nacional de Resíduos Sólidos, mas a um trabalho interdisciplinar que busca a sustentabilidade e uma proposta de modelo de desenvolvimento regional, já que os resíduos sólidos remanescentes deste processo de desenvolvimento incutido na população devem receber destinação apropriada conforme a lei, minimizando os impactos ambientais oferecidos.

\section{CONCLUSÃO}

Debater a gestão dos resíduos sólidos urbanos é amadurecer a relação entre legislação, sociedade e meio ambiente, para que a prática coexista com a teoria, em condições e instrumentos adequados permitindo o caminhar da conservação e proteção da biodiversidade e ecossistemas. A análise da história permite aprender com erros passados e propor soluções que levem a uma assertividade nas ações futuras, através de propostas dimensionadas para a realidade dos municípios pesquisados pela descrição e comparação das práticas adotadas e seus impactos ambientais, econômicos e sociais.

Através da discussão espera-se ampliar a compreensão de que a cultura presente na sociedade com relação aos resíduos sólidos urbanos e a falta de informação sistematizada e periódica são fatores que dificultam a implantação de sistemas de gestão de resíduos sólidos urbanos. Entender as formas de utilização, organização e exploração do trabalho na catação dos resíduos sólidos recicláveis nos lixões e a inserção desses trabalhadores no circuito econômico destacando a organização dos trabalhadores, os programas de coleta seletiva e o comércio dos produtos recicláveis e sua interação no circuito econômico e das estruturas de poder e do controle social serão a base para o planejamento de gestão ambiental e territorial.

\section{REFERÊNCIAS}

ARAUJO, Carolina Lopes; NASCIMENTO, Elimar; VIANNA, João Nildo de Souza. Para onde nos guia a mão invisível? Considerações sobre os paradoxos do modelo econômico hegemônico e sobre os limites ecológicos do desenvolvimento. In: Revista Desenvolvimento e Meio Ambiente. Vol.31, agosto 2014, p 9-18

BEZERRA, J. P. P. - Gestão integrada de resíduos sólidos urbanos nos municípios da UGRHI-14 Alto Paranapanema: interfaces concretas e potencialidades - Tese de Doutoramento apresentada ao PPGG - UNESP FCT Pres. Prudente, 2015

CAPRA, Fritjof. A Teia da Vida. Ed. Pensamento-Cultrix Ltda,1996.

CARSON, Rachel. Primavera Silenciosa. 2a ed. São Paulo: Melhoramentos, 1969.

CUNHA, Sandra B da, GUERRA, Antônio José T. (org.) A Questão Ambiental: diferentes abordagens. 4a ed. Rio de Janeiro: Bertrand Brasil, 2008. 
DRUCKER, F. Peter. O melhor de Peter Drucker: o homem, a administração, a sociedade. Nobel, 2002.

KÖCHE, José Carlos. Fundamentos de Metodologia Científica - teoria da ciência e iniciação à pesquisa. 22a ed. Rio de Janeiro: Vozes, 1997.

LAKATOS, Eva Maria; MARCONI, Maria de Andrade. Fundamentos de Metodologia Científica. 6a ed. São Paulo, Atlas, 2005.

LEAL, Antonio Cezar. Resíduos sólidos no Pontal do Paranapanema. A. Thomaz Junior, 2004.

GONÇALVES, Marcelino Andrade. O trabalho no lixo. Presidente Prudente. FCT- UNESP, 2006

RAMPAZZO, Lino. Metodologia Científica: Para alunos de Graduação e Pós Graduação. 2o ed. São Paulo: Saraiva, 2004.

RODRIGUEZ, J. M. M.;SILVA, E.V. Planejamento e gestão ambiental: subsídios da geoecologia das paisagens e da teoria geossistêmica. 1a ed. Fortaleza: Edições UFC, 2013. 